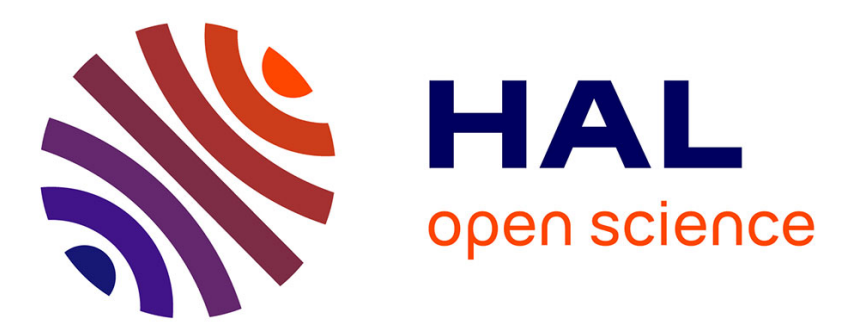

\title{
Customer/Supplier Relationship: reducing Uncertainties in Commercial Offers thanks to Readiness, Risk and Confidence Considerations
}

Abdourahim Sylla, Élise Vareilles, Michel Aldanondo, T. Coudert, L. Geneste, K. Kirytopoulos

\section{To cite this version:}

Abdourahim Sylla, Élise Vareilles, Michel Aldanondo, T. Coudert, L. Geneste, et al.. Customer/Supplier Relationship: reducing Uncertainties in Commercial Offers thanks to Readiness, Risk and Confidence Considerations. JCM 2016 - International Joint Conference on Mechanics, Design Engineering and Advanced Manufacturing, Sep 2017, Catane, Italy. p. 1115-1122, 10.1007/978-3319-45781-9_111. hal-01599430

\author{
HAL Id: hal-01599430 \\ https://hal.science/hal-01599430
}

Submitted on 17 Oct 2017

HAL is a multi-disciplinary open access archive for the deposit and dissemination of scientific research documents, whether they are published or not. The documents may come from teaching and research institutions in France or abroad, or from public or private research centers.
L'archive ouverte pluridisciplinaire HAL, est destinée au dépôt et à la diffusion de documents scientifiques de niveau recherche, publiés ou non, émanant des établissements d'enseignement et de recherche français ou étrangers, des laboratoires publics ou privés. 


\title{
Customer/Supplier Relationship: reducing Uncertainties in Commercial Offers thanks to Readiness, Risk and Confidence Considerations
}

\author{
A. SYLLA ${ }^{1,2}$, E. VAREILLES ${ }^{1}$, M. ALDANONDO ${ }^{1 *}$, T. COUDERT ${ }^{2}, \quad$ L. \\ GENESTE $^{2}$ and K. KIRYTOPOULOS ${ }^{3}$ \\ ${ }^{1}$ Univ. de Toulouse / Mines Albi / CGI - France \\ ${ }^{2}$ Univ. de Toulouse / ENI Tarbes / LGP - France \\ ${ }^{3}$ National Technical Univ. of Athens - Greece \\ * Corresponding author. Tel.: +33 - 5634932 34; fax: + 33 - 5634931 83. E-mail address: \\ michel.aldanondo@mines-albi.fr
}

\begin{abstract}
Nowadays, in customer/supplier relationship, suppliers have to define and evaluate some offers based on customers' requirements and company's skills. This offer definition implies more and more some design activities for both technical solution and its delivery process. In the context of Engineering-To-Order, design and engineering activities are more important, the uncertainties on offer characteristics is rather high and therefore, suppliers bid on the calls for tender depending on their feelings. In order to provide suppliers with metrics that enable him/her to know about the confidence level of an offer, we propose a knowledgebased model that includes four original metrics to characterize the confidence level of an offer. The offer overall confidence relies on four indicators: (i) two objectives ones based on Technology Readiness Level and Activity Risk Level, and (ii) two subjective ones based on the supplier's skills and risks aversion. The knowledge-based model for offer definition, offer assessment and offer confidences is based on a constraint satisfaction problem.
\end{abstract}

Keywords: Customer/Supplier Relationship; Knowledge-Based Systems; Readiness; Maturity; Confidence

\section{Introduction}

The proposed paper concerns the assistance of a supplier in a customer/supplier relationship. More accurately, it aims at aiding the definition of a commercial offer for both system (product, system or service) and delivery process. The presented contribution belongs to the stream of works that deals with the set-up of knowledge-based tools aiding the system-process definition (that can include 
some design activities) and supporting the quotation of performance, cost and cycle time [1]. In this offer definition context, the system-process definition can vary from a very routine activity up to a highly creative and so far much less routine one [2]. For example let us consider a computer system or a truck, the definition of an offer consists mainly in selecting some options and components in a catalogue, checking their consistency and computing a cost and a standard delivery time. At the opposite, the definition of an offer for a crane or for a specific machine-tool can require significant engineering or creative design activities for both system solution and delivery process. Given these elements, the customer/supplier relationship can be characterized, according to [3], as either very routine assembly-to-order (ATO) or make-to-order (MTO) offer definition, or much less routine engineer-to-order (ETO) offer definition. For 20 years now, configuration software's have been recognized as very efficient tools for aiding suppliers in their offer definition activity in ATO-MTO situations [4]. When dealing with ETO, it is less the case because the design activity is more consequent and thus Computer Aided Design software must be used. It is important to note that ATO-MTO or ETO is not a binary issue. In an ATO-MTO situation, all design problems for both system solution and delivery process have already been studied and solved in advance before launching the activity of the offer definition (in a very formal way if a configuration software is used). Therefore, the level of uncertainty in the offer characteristics is rather low and the supplier feels very confident in the fact that the defined offer matches the customer's expectations (including price and due date). When the situation begins to move from ATO-MTO towards ETO, design or engineering activities are more significant. Two kinds of approaches can be seen in companies for the offer definition activity. The first one relies on a detailed design of offers for both system solutions and delivery processes. Thus uncertainties are low and supplier's confidence is high but this approach is time and resources consuming. On the opposite, the second one tends to just clarify the main ideas or concepts about offers avoiding detailed design, but leaving a great deal of uncertainty and a scant confidence.

Given all previous elements, the goal of this paper is to propose a theoretical approach and a knowledge-based model aiding suppliers to define promising offers: for "rather" routine design situation in order to be able to collect knowledge, for situation "between" ATO-MTO and ETO, when more than $50 \%$ of system subassemblies and process activities are entirely defined, that avoids the entire detailed design of offers by saving time and resources' commitment and strengthens the confidence in the main ideas or concepts about offers.

Our main and original contribution is to add a new characteristic or indicator to system-process offers that can quantify a kind of "confidence level" (in a similar sense as the one proposed by [5]. This means that each sub-assembly, each delivery process activity and resulting system-process is characterized with its own "confidence level". This new indicator allows the supplier to compare competing solutions on: performance, cost, lead time but also, and we have never seen that in the scientific literature, confidence. The suppliers feel now more self-confident to 
decide about the offer to propose to the customer whatever the stage of its development. In nowadays highly competitive markets, where customers don't hesitate to compare various suppliers through competitive process, the confidence indicator is a strong supplier support that avoids detailed designs while having a clear quantification of offer confidence. Knowing the confidence level of each offer element reduces the stress of a supplier in the decision making and helps him/her during offers negotiations.

The remaining of the paper is organized in three sections as follows. In a second section, the main ideas about concurrent configuration of system and process for ATO-MTO and ETO situations are recalled and the support provided by the Constraint Satisfaction Problem framework is explained. The third section is dedicated to the proposition of the "confidence level" indicator with various aggregation mechanisms for both system solutions and delivery processes. In the last section, some conclusions are drawn and further perspectives are developed.

\section{Offer Configurations in ATO-MTO-ETO Situations}

When dealing with concurrent configuration of product and process problem, $[6,7]$ have shown that the product can be considered as a set of components and its production process as a set of production operations.

According to the customer's expectations, the configuration of a product is achieved either by selecting components in product families (as an engine in a catalogue) or choosing values of descriptive attributes (power and weight of an engine). Of course all combinations of components and attribute values are not allowed. Thus, as explained by many authors [8,9], the product configuration problem can be considered as a discrete constraint satisfaction problem (CSP), where a variable is a product family or a descriptive attribute and constraints specify acceptable or forbidden combinations of components and attribute values. Some kind of product performance indicators can characterize the product, thanks to some mixed constraints (symbolic and numerical domains) that link the most important product characters (for example : crane performance function of crane height and acceptable load).

For process configuration, a similar approach is proposed by [10,11]. According to the configured product characteristics (selected components and attributes values), the resources for each production operation can be selected in families of resources, and in some case a quantity of resource can be specified too. Of course, selected components and values (for products) and selected resources and quantities (for operations) impact operation durations and therefore the production process delivery time or cycle time of the configured product. For simplicity, we assume a sequence of operations and therefore that the lead time equals the sum of operation durations. As for product, process configuration can be considered as a CSP, where each operation gathers variables corresponding to resource families, 
resource quantities and operation duration [12]. Constraints restrict possible associations.

For both product and process, all variables can be linked to cost indicators (one for product and one for process) with again some mixed constraints in order to get a total cost. With the previous problem descriptions, [10,11] have suggested (i) to gather these two problems into a single concurrent problem and (ii) to consider this concurrent problem as a CSP. Considering this problem as a CSP, allows the use of propagation or constraint filtering mechanisms as an aiding tool. Each time a customer's expectation is inputted (mainly in the product and less in the process), constraints propagate this decision and prune variables values for descriptive attributes, component families, resources families, resources quantities, operation duration and then update performance, cycle time and total cost. For a detail presentation with an easy to understand example, we deeply suggest to consult [13]. This kind of problem modeling is the ground basis of configuration problems. The key point is that all possible solutions have been studied in advance meaning that all product families and relevant components, all attributes with their possible values, all process operations with their resource families and resources have been analyzed and qualified before operating the configuration system. Thus the configuration process is infinitely routine and there is absolutely no design or creative activity. In that case, when the customer says ok, the detailed design of both product and process is almost automatically generated without any doubt or uncertainty and thus the supplier is fully confident in his/her ability to achieve his/her commitments, with no unnecessary stress.

Moving from products to systems is trivial. We assume for systems: (i) a system is a set of sub-systems (ii) a sub-system is represented by a set of descriptive attributes and one family of technical solutions (equivalent to a component family). For processes, the model is absolutely the same. Same indicators, performance, lead time and cost are kept. All interdependencies, restrictions between system and process variables are modeled with discrete constraints. All indicator computations are supported by mixed constraints. From now, we will speak only of configuration of systems (and not only products) and processes.

Moving from ATO-MTO to ETO means that some engineering activities either to design new sub-systems or to finalize the design are necessary in order to satisfy the customer's requirements. For the system side, moving from ATO-MTO to ETO means that the system is new and has never been designed completely because: (1) at least, one of its sub-systems has to be designed in order to answer to the customer's requirements, or (2) the system is composed of a set of existing sub-systems which have never been assembled together. For the delivery process side, moving from ATO-MTO to ETO means that some engineering activities have to be carried out in order to design or finalize the design of the system therefore: (1) new engineering activities can be added to the delivery process and tuned or (2) the process durations (design and production activities) can be updated to take into account the engineering activity. 


\section{3 - Offer Overall Confidence Definition}

This section is dedicated to the definition of the offer overall confidence indicator. We propose that this new and original indicator relies on two pairs of specific indicators, one pair characterizing the system solution, and the other one, the delivery process. Each pair of indicators is composed of one objective indicator and its pre-defined scale whereas the second one is much more subjective and supplierdependent. First, objective indicators are presented for the system and process sides, then, are the subjective ones. This section finishes with the first aggregation mechanisms in order to compute the offer overall confidence, and how this information can help suppliers in decision making.

Objective indicators give reliable unbiased information on system solutions and delivery processes and characterize the readiness of technology used for the system solution and the risks level for the delivery process. We propose to add to each sub-system of the system solution and each activity of the delivery process, these new objective indicators. Let's start with the system side. The offer overall confidence relies at least partially on the readiness of technology used in the system solution. Indeed, the technology readiness level or TRL indicates how much a system is ready to be deployed. TRL is a systematic metric/measurement developed by $[14,15,16]$ at US National Aeronautics and Space Agency (NASA) for the measure of the maturity of technologies. It has been adopted by US government organizations like US Department of Defence (DoD) and US Department of Energy (DoE), by Industry and increasingly internationally [17,18]. TRL is based on a scale from 1 to 9 with 9 being the most mature [19]. In our proposal, for each sub-system, we associate to each technical solution (of its family of technical solutions) a TRL. Therefore, selecting a technical solution for a sub-system leads to the identification of the correct TRL. Let's now move to the process side. The offer overall confidence relies also on the risks taken by the supplier in case of success, meaning that he/she has won the tender. Indeed, every business is exposed to risks all the time and such risks can directly affect day-to-day operations, decrease revenue or increase expenses. Their impact may be serious enough for the business to fail. As far as we know, there is no way to characterize the risk level for each activity of a delivery process. Therefore, based on the CMMI and TRL, we propose the first version of ARL, for Activity Risks Level, based on a nine-level scale. This nine-level scale is dedicated to the main risk of an activity and relies on the main risk probability of occurrence (high or low), the main risk impacts (serious or marginal) and the main risk treatments (it exists or not action plans to manage the risk). In our proposal, for each activity, we associate an ARL. Depending on the model and knowledge, ARL can be modified by the selection of adequate resources and valuation of their quantity.

Subjective indicators reflect more the supplier feelings about the offer and rely on his/her skill, expertise and point of view on the whole situation as well as his/her risk aversion. Indeed, the fact that all the technologies selected for the sys- 
tem solution are ready to be deployed does not guaranty that the system solution matches customer expectations. Moreover, certainly, not all sub-systems need a maximum readiness level as a prerequisite for an application $[15,16]$ and inversely, a given readiness level is not sufficient for selecting a technical solution. Following the same reasoning for the process side, the fact that all the activities of the delivery process have their main risk level at 9 with low probability of occurrence, marginal impact and plenty of treatments does not guaranty that the delivery process will run correctly, without any hazard and any delay or additional cost. We therefore propose the first version of SFL, for Supplier Feeling Level, based on a three-level scale. This three-level scale corresponds to the feeling (bad, neutral or good) of the supplier about the offer. In our proposal, we associate an SFL to each sub-system of the system solution and each activity of the delivery process.

The offer overall confidence relies at the same time on TRL and SFL of the system side and ARL and SFL of the process side. Some aggregation mechanisms are needed at each level of the bill-of-material for the system solution, for the complete set of activities for the delivery process and also for the overall offer.

Let's start with the system side. When a system is composed of several subsystems, its readiness level depends on the TRL of each of its sub-systems and of the readiness of their integration or IRL [19]. Then, the readiness of each system SRL is computed using TRLs and IRLs. Several SRL calculation methods have been proposed in the literature: matrix algebra [19,20,21] or tropical algebra approach [22]. The most used SRL calculation method is the one proposed in [19] and it is the calculation method adopted in this paper. This method leads to a fivelevel scale for SRL. We propose to use the same aggregation method for the subjective indicators SFL of the system by taking into account the SFL of each subsystem as well as the SFL of their integration. Let's continue with the process side. After determining the ARL of each activity of the delivery process, the risk level of the whole delivery process or PRL has to be computed. It is important to recall here that the phenomenon of integration as described in a system does not exist in the delivery process. As a first stage, we propose to use an average method based on ARL to compute the PRL as well as its subjective indicators SFL of the activities. Let's finish with the offer overall confidence. The offer overall confidence relies on both system solution and delivery process and therefore should weight them equally. Therefore, as a first stage, we propose a two-step approach to compute the offer overall confidence. First, the objective indicators SRL and ARL are modulated by the subjective ones SFL: a good feeling increases the indicator, a bad feeling decreases it and a neutral one has no impact. The supplier has to specify how much it goes up and down. Second, the offer overall confidence is computed as the average of the modulated indicators. 


\section{4 - Conclusion}

In this paper, we have proposed an original way to assess confidence in offers while bidding, from the supplier or bidder point of view. Our proposals are based on the extension of configuration process from ATO-MTO towards ETO situation. This extension is necessary as some configurations have never occurred and some others require systems to be specifically designed then produced. In order to cope with ETO situation, specific values have been added to the configuration models with a specific meaning.

Then, we have proposed three new indicators to measure the degree of confidence in the overall offer. Two of them are objective and independent of the supplier (TRL and ARL). They characterize the readiness level of each sub-system and the risk level of each activity and are both based on a nine-level scale. The last one is more subjective and relies on the supplier feelings (SFL) about the offer and rely on his/her skill, expertise and point of view on the whole situation as well as his/her risk aversion. Aggregation mechanisms have been proposed in order to compute the SRL of the system solution, the PRL of the whole delivery process and the SFL for both system and process. In order to compute the offer overall confidence, objective indicators SRL and PRL are modulated by their respective SFL. Then, the offer overall confidence is computed as the average of modulated SRL and PRL.

With these three original indicators TRL, ARL and SFL and the proposed aggregation mechanisms, a supplier is now able while designing system solutions and delivery processes, to evaluate one or several offers with: (i) conventional indicators (cost, lead time and performance) and also (ii) objective and subjective confidence. Thus, the supplier can select the better one with less stress and a better confidence. These proposals have been confirmed by several companies in system and service sectors. We have now to test it on real cases and to improve it with much more sophisticated aggregation methods. The use of Case-Based Reasoning and experience feedbacks will be used to support the supplier in the valuation of the subjective indicators and the model updates.

\section{Referencing}

1. W.J.C. Verhagena, P. Bermell-Garciab, R.E.C. van Dijkc, R. Curran - A critical review of Knowledge-Based Engineering: An identification of research challenges - Advanced Engineering Informatics Volume 26, Issue 1, pages 5-15, 2012.

2. B. Chandrasekaran - Design problem solving : a task analysis. In Artificial Intelligence Magazine, Volume 11, pages 59-71, 1990

3. J. Olhager - Strategic positioning of the order penetration point - International Journal of Production Economics - Volume 85, Issue 3, pages 319-329, 2003.

4. A. Felfernig, L. Hotz, C. Bagley, J. Tiihonen - Knowledge-based Configuration From Research to Business Cases - Morgan Kaufmann - 2014. 
5. MR Endsley, D.G Jones - Chapter 7 Confidence and Uncertainty in situation awareness and decision making - Designing for situation awareness, Taylor \& Francis, pages113-121 - 2004. 6. S. Mittal, F. Frayman - Towards a generic model of configuration tasks, in: Proceedings of IJCAI, pp. 1395-1401, 1989.

7. M. Aldanondo, E. Vareilles - Configuration for mass customization: how to extend product configuration towards requirements and process configuration - Journal of Intelligent Manufacturing, Volume 19, Issue 5, pages 521-535, 2008.

8. T. Soininen, J. Tiihonen, T. Mannisto, R. Sulonen - Towards a general ontology of Configuration - Artificial Intelligence for Engineering Design, Analysis and Manufacturing Volume 12 Issue 4, pages 357-372, 1998.

9. D. Sabin et R. Weigel - Product configuration frameworks - A survey - IEEE Intelligent System and their Applications, Volume 13, Issue, pages 42-49, 1998.

10. P Pitiot, M Aldanondo, E Vareilles - Concurrent product configuration and process planning: Some optimization experimental results - Computers in Industry, Volume 65, Issue 4, Pages, 610-621, 2014.

11. LL Zhang, Q Xu, Y Yu, RJ Jiao - Domain-based production configuration with constraint satisfaction - International Journal of Production Research, Volume 50, Issue 24, pages 71497166, 2012.

12. R. Bartak - Constraint satisfaction for planning and scheduling problems. - Constraints, Volume 16, Issue 3, pages 223-227, 2011.

13. P Pitiot, M Aldanondo, E Vareilles, P Gaborit, M Djefel, S. Carbonnel- Concurrent product configuration and process planning, towards an approach combining interactivity and optimality - International Journal of Production Research, Volume 51, Issue 2, Pages 524-541, 2013.

14. S.R. Sadin, F.P. Povinelli, - The NASA Technology Push Towards Future Space Mission Systems - Acta Astronautica Volume 20, pages 73-77, 1989.

15. J. C. Mankins - TECHNOLOGY READINESS LEVELS, A White Paper - Office of Space Access and Technology NASA, 1995.

16. J. C. Mankins- Technology Readiness Assessments: A Retrospective - Acta Astroutica, Volume 65, Issue 9-10, pages: 1216-1223, 2009.

17. Sauser, B.J., D. Verma, J. Ramirez-Marquez, and R. Gove. (2006). From TRL to SRL: The Concept of Systems Readiness Levels. Conference on Systems Engineering Research, April 7-8, Los Angeles, CA, 2006.

18. R. Magnaye, B. Sauser, P. Patanakul, D. Nowicki, W. S. Randall - Earned readiness management for scheduling, monitoring and evaluating the development of complex product systems - International Journal of Project Management, Volume 32, Issue 7, 2014.

19. W. Tan, J.E. Ramirez Marquez, B. Sauser - A Probabilistic Approach to System Maturity Assessment - Systems Engineering, Volume 14, Isuue 3, pages: 279-293, 2011.

20. London, M. A., Holzer, T. H., Eveleigh, T. J., \& Sarkani, S. (2014). Incidence matrix approach for calculating readiness levels. Journal of Systems Science and Systems Engineering, 23(4), 377-403.

21. J. E. Ramirez-Marquez, B. J. Sauer - System development planning via system maturity optimization - Engineering Management, IEEE Transactions, Volume 56, Pages 533-548, 2009

22. McConkie, E., Mazzuchi, T. A., Sarkani, S., \& Marchette, D. (2013). Mathematical properties of system readiness levels. Systems Engineering, 16(4), 391-400. 